\title{
Optimal reproductive strategies in age-structured populations of zooplankton
}

\author{
ROBERT M. DORAZIO and JOHN T. LEHMAN Division of Biological Sciences, \\ The University of Michigan, Ann Arbor, Michigan
}

\begin{abstract}
SUMMARY. We describe a model of zooplankton population dynamics that accounts for differences in mortality and physiology among animals of different ages or sizes. The model follows changes in numbers of individuals and changes in individual and egg biomass through time and it expresses mortality and net assimilation as functions of animal size.

We investigated the effect of egg size, age at first reproduction, and size at first reproduction on the per capita growth rates of populations growing under different conditions. In the absence of predation or when exposed to vertebrate predators that prefer large prey, populations achieve maximum growth rates when animals hatch from small eggs and reach maturity quickly at small sizes. Populations exposed to invertebrate predators that concentrate on small animals may increase $r$ in two different ways. One way is for animals to increase juvenile survivorship by hatching from large eggs and by shortening the juvenile period. An alternative strategy is for animals to hatch from small eggs and to postpone maturity until they grow beyond the range of sizes available to their predators. Certain life history strategies maximize $r$ if animals continue to grow after they reach maturity. By growing larger, non-primiparous females are able to hatch larger clutches and thereby increase the overall rate of population growth.

The model analysis shows how to assess age-dependent mortality rates from field data. The net rate of population increase and the age distribution of eggs together provide specific, quantitative information about mortality.
\end{abstract}

\section{Introduction}

Simulation models of plankton communities have become progressively more detailed in the ways uptake kinetics, cell quotas, growth rates, and growth interactions of algae are treated (Scavia \& Park, 1976; Steele \& Frost, 1977;

Correspondence: Dr Robert M. Dorazio, Division of Biological Sciences, Natural Science Building, The University of Michigan, Ann Arbor, Michigan 48109, U.S.A.
Collins, 1980). In contrast, the models have made little progress in the ways that growth and dynamics of zooplankton populations are treated. Complex formulations exist describing grazing activities of zooplankton (Steele \& Frost, 1977), but most attempts to model the dynamics of single populations assume that all animals are physiologically identical regardless of age or size. Calculations are based on increments or decrements to a pool of 'zooplankton 
biomass' (e.g. Park et al., 1974). Differences between juveniles and adults, for instance, are often ignored, leading to the implicit but incorrect premise of constant physiology throughout life. Natural populations do not exhibit this constancy. Differences in individual growth rates and probabilities of death during the life history of an animal control the age structure of real populations. Zooplankton are exposed to predators that specialize on particular size classes of the population. Many vertebrate predators such as fish and salamanders prefer large species of zooplankton or the larger members of single populations (Brooks \& Dodson, 1965; Dodson, 1974). Many invertebrate predators, on the other hand, prefer smaller prey and select for small size classes (Fryer, 1957; Kerfoot, 1977). Depending on the situation, natural populations of zooplankton may experience many alternative age or sizespecific mortality regimes, and a realistic model of a population's growth and dynamics must account for such selective behaviour.

Even among models that specifically aim to decipher the population dynamics and secondary production of zooplankton (Edmondson, 1968;
Caswell, 1972; Argentesi, de Bernardi \& di Cola, 1974; Paloheimo, 1974), there is disagreement about how to estimate fundamental characteristics like per capita birth and death rates (Seitz, 1979). The models rely on simplistic assumptions about the age distribution of the population (e.g. uniform age distribution in Edmondson's (1960) egg ratio model) and then proceed without specific reference to error introduced by the assumptions. A notable exception is the three-stage model for exponentially growing populations proposed by Taylor \& Slatkin (1981). These authors examined errors in estimates of per capita birth rates that result from measurement errors and from the time and age-dependence of the population's actual birth and death rates. Taylor \& Slatkin's efforts to evaluate the assumptions of their model against a rigorous standard before accepting them signal a major conceptual advance.

Perhaps the most interesting reason for examining models of zooplankton population dynamics is to study life history characteristics like egg size, age and size at first reproduction, and egg development time. These parameters are under intense selective control and respond

TABLE 1. Parameter values used in simulations

\begin{tabular}{|c|c|c|c|c|}
\hline \multicolumn{3}{|c|}{ Parameter } & \multirow{2}{*}{$\frac{\text { Simulation value }}{2-12 \text { days }}$} & \multirow{2}{*}{$\begin{array}{l}\text { Reference } \\
\text { Korstad (1980); } \\
\text { Lynch (1980a) }\end{array}$} \\
\hline${ }^{*} a_{A}$ & $=$ & age at maturity & & \\
\hline${ }^{*} S_{A}$ & $=$ & size at maturity & $0.2-2.2 \mathrm{~mm}$ & Lynch (1980a) \\
\hline$D_{e}$ & $=$ & egg development time & 2 days & Bottrell et al. (1976) \\
\hline & & assimilation rate constant & 1.8 & Lampert (1977) \\
\hline$b$ & $=$ & assimilation rate constant & -0.33 & Lampert (1977) \\
\hline$a^{\prime}$ & $=$ & assimilation rate constant & 0.2 & Lampert (1977) \\
\hline$b^{\prime}$ & $=$ & assimilation rate constant & -0.12 & Lampert (1977) \\
\hline${ }^{*} R$ & $=$ & $\begin{array}{l}\text { fraction of assimilate } \\
\text { allocated to reproduction }\end{array}$ & 1.0 & - \\
\hline$R_{e}$ & $=$ & $\begin{array}{l}\text { egg respiration/ } \\
\text { excretion rate }\end{array}$ & $0.1 /$ day & - \\
\hline${ }^{*} E$ & $=$ & mass of a newly laid egg & $0.2-2.4 \mu \mathrm{gC}$ & Dumont et al. (1975) \\
\hline$R v$ & $=$ & $\begin{array}{l}\text { smallest apparent prey size } \\
\text { for a vertebrate predator }\end{array}$ & $1.2 \mathrm{~mm} / \mathrm{animal}$ & - \\
\hline$S v$ & $=$ & $\begin{array}{l}\text { lower limit to size range } \\
\text { over which intensity of } \\
\text { vertebrate predation is } \\
\text { maximal }\end{array}$ & $1.8 \mathrm{~mm} /$ animal & - \\
\hline Riv & $=$ & $\begin{array}{l}\text { largest prey size for an } \\
\text { invertebrate predator }\end{array}$ & $1.4 \mathrm{~mm} /$ animal & - \\
\hline Siv & $=$ & $\begin{array}{l}\text { upper limit to size range } \\
\text { over which intensity of } \\
\text { invertebrate predation is } \\
\text { maximal }\end{array}$ & $0 \mathrm{~mm} /$ animal & - \\
\hline
\end{tabular}

*Denotes parameters for which values were varied among simulations. 
to changes in predation, food availability, and other environmental conditions. Variability in life history strategies and reproductive traits among zooplankton is well documented (Hutchinson, 1967; Allan \& Goulden, 1980; Lynch, 1980a), but there have been few attempts to determine how selective pressures can affect optimal reproductive strategies (Lynch, 1977, 1980b).

We present a set of formulations to attack this problem. Our model simulates the growth and dynamics of zooplankton populations with continuous recruitment from animals of different ages. This reproductive pattern is most clearly exemplified by cladocerans, such as Daphnia, and by rotifers. Processes important in population growth such as recruitment and mortality are formulated to reflect the reproductive patterns and mortality schedules common to these animals. By allowing these processes to be invariant through time, we can generate stable age distributions (Lotka, 1925) and per capita growth rates of populations under different mortality regimes and environmental conditions. In that way our mathematical constructs imitate some of the experimental conditions maintained in continuous cultures of zooplankton (e.g. Droop, 1973; Boraas, 1980). By comparing growth rates for model populations with different reproductive traits we can determine optimal life history strategiès under different selective pressures. Investigations of optimal reproductive strategies for populations exposed to variable environmental conditions are equally important, and we developed this model so that it can be coupled to models of phytoplankton growth and grazing loss. Looking at life history tactics for populations exposed to seasonal changes in food availability and predation will be the subject of another paper.

Because our model computes per capita birth and death rates as well as age structure, we can identify and interpret the biases inherent in simpler models that seek to calculate those rates from field data. Our aim is not to create a complex model of zooplankton growth and dynamics for its own sake but rather to illustrate the consequences of age-specific recruitment and mortality to any analysis of zooplankton populations. Using our model we demonstrate that some more simplified analyses are valid, a procedure that we regard as more secure than accepting simplifications $a$ priori.

\section{Methods}

\section{Equations of growth}

Early attempts to model zooplankton populations on an age-specific basis (Slobodkin, 1954; Frank, 1960) showed that population growth was best predicted when both numbers and biomass of individuals were followed through time. We therefore make the number of individuals a continuous function of age, time and size, as in the 'density function' approach taken by Sinko \& Streifer (1967). Whereas age and time are explicitly linked, age may also be related to size if the initial egg size, the food assimilation function, and the fraction of assimilate allocated to growth is specified. Table 1 lists these parameters with notations and values used in our model. Consider the age distribution of the population at time $t$ (Fig. 1). This is a hypothetical plot of the numbers of individuals of a given age, $N(a)$, against age, $a$. The age at maturity $a_{A}$ separates juveniles from adults. Instars may be identified as intervals on the abscissa. Egg laying and egg hatching occur as discrete events for individuals of ages $a_{A}+j D_{e}$ where $D_{e}=$ egg development time and $j=1,2, \ldots$. The area under the curve is equal to the total number of individuals in the population at time $t, N(t)$, and is given by

$$
N(t)=\int_{0}^{\infty} N(a) d a
$$

Because age structure can change with time, we divide the age axis into intervals of width $\Delta a$ and characterize processes which add and subtract individuals to and from each age class during the time interval $\Delta t$. Ignoring immigration and emigration,

$$
\begin{aligned}
& \text { Change in number Recruitment in } \\
& \text { of individuals = from preceding } \\
& \text { during } \Delta t \quad \text { age class } \\
& \begin{array}{ll}
\text { Recruitment } & \text { Mortality } \\
\text { out to next } & - \text { incurred } \\
\text { age class } & \begin{array}{l}
\text { while in age } \\
\text { class }
\end{array}
\end{array}
\end{aligned}
$$

Mathematically this equation may be defined as:

$$
\frac{\Delta N(a)}{\Delta t}=\frac{N(a-\Delta a)-N(a)}{\Delta a}-m N(a)
$$

where $m$ represents the fraction of individuals lost to mortality during $\Delta t$. This fraction is related to all sources of mortality (predation, natural death, etc.) and is a function of an 


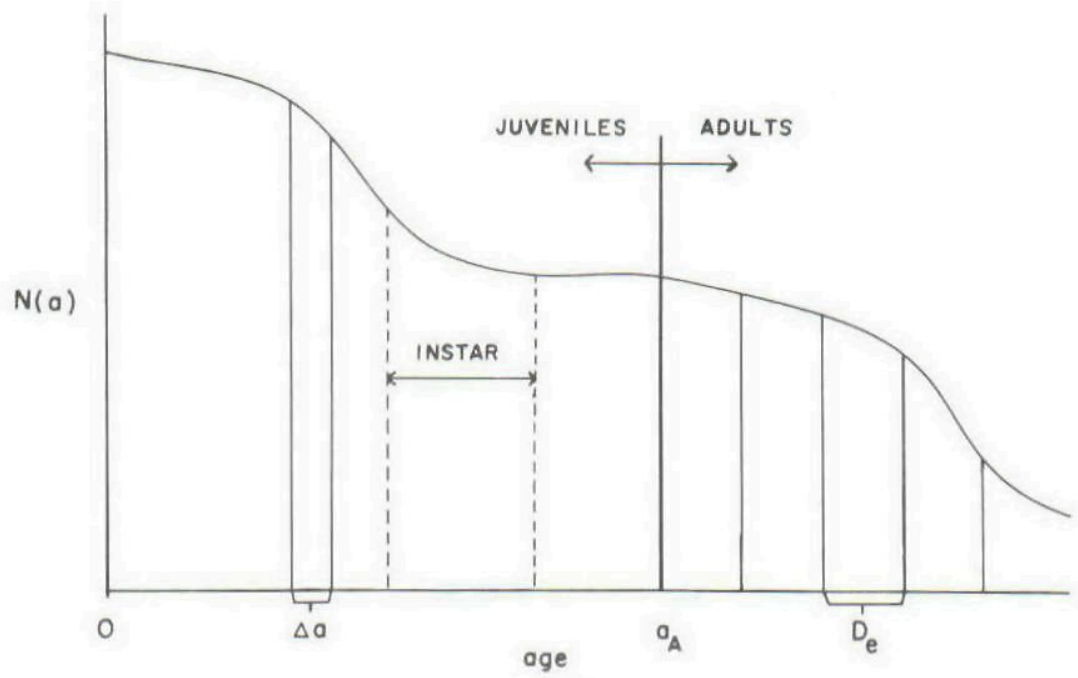

FIG. 1. Instantaneous profile of the age distribution of a zooplankton population.

animal's age, $m=m(a, t)$. As time and age are explicitly linked, the differences in number of animals added to and subtracted from any age class via recruitment must be divided by a finite period of time $(\Delta a)$ that defines individuals within an age class. Assumptions are best approximated when $\Delta a$ is very small. Taking the limit of eqn (3) as $\Delta a \rightarrow 0$ and $\Delta t \rightarrow 0$, yields

$$
\frac{\partial N}{\partial t}=-\frac{\partial N}{\partial a}-m N
$$

Equation (4) is cited in more general form by Von Foerster (1959) and Streifer (1974, eqn 13). We omit explicit expression of $N$ and other variables as functions of age and time (e.g. $N=$ $N(a, t))$ to simplify notation. The partial derivatives with respect to age and time have opposite signs because recruitment into a fixed age class over time occurs from younger age classes.

We assume size or biomass of an animal is a continuous function of its age. In order to simulate the animal's physiology and life history we begin with the following definitions:

$$
\begin{aligned}
B t(a, t)= & \text { biomass of structural tissue and } \\
& \text { tissue being used to manufacture } \\
& \text { eggs (total biomass of animals of } \\
& \text { age } a \text { at time } t \text {, not including eggs } \\
& \text { or embryos outside the ovaries). } \\
B s(a, t)= & \text { biomass of structural tissue only } \\
& \text { for animals of age } a \text { at time } t ; \\
& \text { animals that have not started }
\end{aligned}
$$

oocyte and yolk production have $B t=B s$.

$B e(a, t)=$ biomass of eggs carried outside the ovaries by adult females of age $a$ at time $t ; B e$ equals zero for juveniles $\left(a<a_{A}\right)$

Biomass increases nonlinearly with age as shown in Fig. 2, a hypothetical plot of total biomass, $B t$, against age. The sharp reductions in total biomass correspond to losses of biomass during egg laying, discrete events which occur every $D_{e}$ units of time after the animal reaches adulthood (i.e. at ages $a_{A}, a_{A}+D_{e}, a_{A}+2 D_{e}, \ldots$ ). After the eggs are laid they develop for $D_{e}$ units of time while being carried by the female culminating in their release from the female during hatching. Although Fig. 2 is drawn for animals that put all net assimilated carbon into egg production upon reaching adulthood, this is a variable feature of an organism's life history, and actually any percentage of assimilate may be allocated to reproduction. The rate at which a zooplankter adds biomass depends on its rate of assimilation. Measurements of gross assimilation rate as defined by Lampert (1977) for several species of zooplankton indicate that the relationship

$$
A_{G}=a B s^{b}
$$

accurately predicts gross specific assimilation rate $A_{G}(\% C / d)$ for a specified temperature and food concentration. The coefficients $a$ and $b$ are 


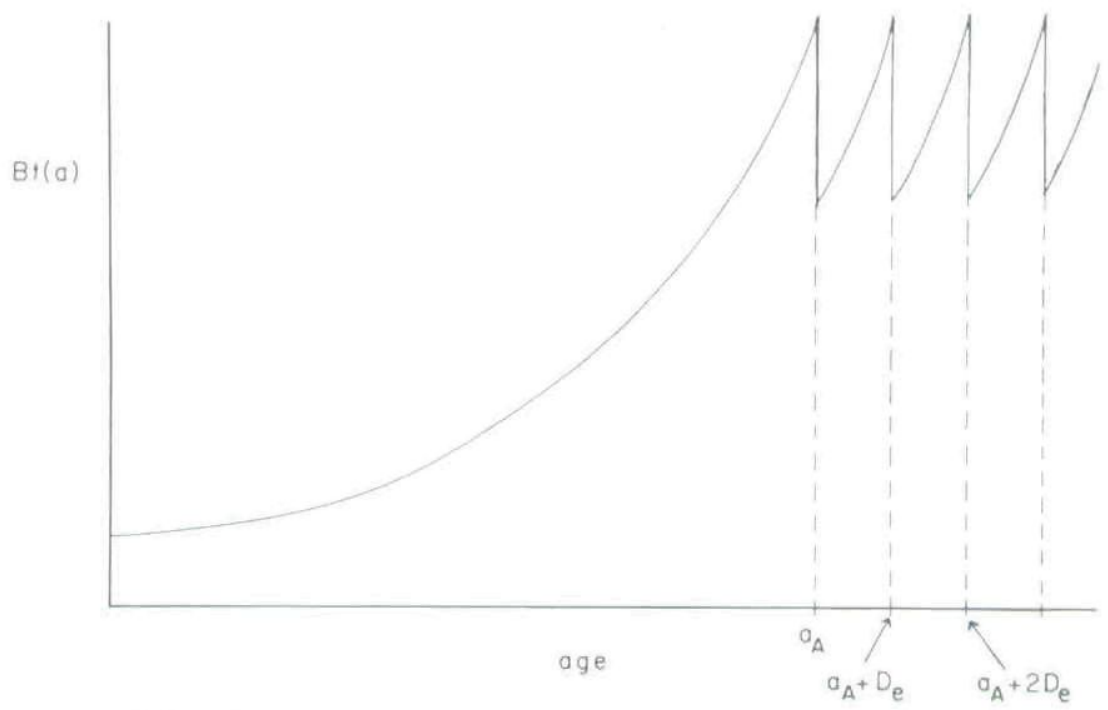

FIG. 2. Instantaneous profile of the age distribution of total biomass, $B t$.

constants depending on the animal and food species (Table 1). To obtain an expression for net assimilation, we subtract a term that corresponds to maintenance losses of carbon

$$
A=a B s^{b}-a^{\prime} B t^{b^{\prime}}
$$

where $a^{\prime}$ and $b^{\prime}$ are again constants (Table 1). Total biomass, $B t$, is used to estimate maintenance because it is a function of the animal's total mass, including reproductive biomass. An adult animal may allocate part or all of its net assimilate to reproduction; the remainder is used for growth. We define $R$ as the fraction of net assimilation that is allocated to reproduction. Obviously $R$ is zero for immature animals. Variation of $R$ allows us to investigate optimal allocation of reproductive effort under different environmental constraints. Changes in structural biomass, $B s$, are therefore represented by

$$
\frac{\partial B s}{\partial t}=-\frac{\partial B s}{\partial a}+A(1-R) B s
$$

where the first term on the right-hand side represents recruitment as before. The second term on the right-hand side of eqn (7) accounts for structural biomass that is added during growth; $A$ and $R$ were defined above. This equation for biomass differs from that for numbers (eqn 4) in the absence of a mortality term. Mortality alters population numbers but not the mass of individual animals of a given age.
Besides recruitment and assimilation, changes in the total biomass of individuals at any given age include losses $(L)$ that occur when eggs are laid:

$$
\frac{\partial B t}{\partial t}=-\frac{\partial B t}{\partial a}+A B s-L
$$

Egg laying is a discrete event in the life history of a zooplankter beginning at reproductive maturity (age $a_{A}$ ) and continuing every $D_{e}$ units of age afterwards. $L$ is simply the difference between structural and total biomass and is imposed every $D_{e}$ units of time on adults of particular ages according to

$$
L= \begin{cases}B t-B s & a=a_{A}+j D_{e} \quad j=0,1, \ldots \\ 0 & \text { otherwise }\end{cases}
$$

Recruitment into the egg biomass pool occurs when eggs are laid ( $L$ as defined in eqn 9$)$. The relation of egg biomass to egg number depends on an egg size parameter ( $E$, Table 1). As the eggs develop they are subject to the same age-specific mortality as their mothers which carry them $(m=m(a, t))$. Decrements to egg biomass result from egg respiration and excretion, and we define an egg respiration and excretion rate, $R_{e}$, as the fraction of egg biomass metabolized each day. At the end of development $\left(\Delta a=D_{e}\right)$ eggs hatch and juvenile animals swim away from their mother into the open water. Simultaneously a 
new clutch of eggs is laid by the female. Therefore egg hatching $(H)$, as with egg laying $(L)$, is a discrete event representing recruitment out of the egg biomass pool every $D_{e}$ units of time:

$$
H= \begin{cases}B e & a=a_{A}+j D_{e} \quad j=1,2, \ldots . \\ 0 & \text { otherwise }\end{cases}
$$

By combining the events that comprise an egg's 'life history', we represent changes in egg biomass carried by individual females by

$$
\frac{\partial B e}{\partial t}=L-H-R_{e} B_{e}
$$

The biomass of newborn animals is simply the sum of all hatching egg biomass, or

$$
\begin{gathered}
N(1) \cdot B s(1)=N(1) \cdot B t(1)=\sum_{a} H(a) N(a) \\
a \geqslant\left(a_{A}+D_{e}\right)
\end{gathered}
$$

We compute the number of newborn individuals, $N(1)$, by dividing total biomass of all hatching eggs $(\mu \mathrm{gC})$ by egg size $(\mu \mathrm{gC} / \mathrm{egg})$ :

$$
N(1)=\left[\sum_{a} H(a) \cdot N(a)\right] /\left[E \cdot\left(1-R_{e}\right)^{D_{e}}\right]
$$

where $E$ is the size of newly laid eggs, and $\left(1-R_{e}\right)^{D_{e}}$ is the fraction of egg biomass not inspired over $D_{e}$ (Table 1). Using the numbers of adult females that hatch eggs implicitly accounts for egg survivorship during development (via eqn 4).

In simulations the age at maturity $\left(a_{A}\right)$ can be treated in two ways. In one, the age may be fixed and animals of this age may vary in size depending on the size of egg they hatched from and their post-embryonic development rate. Alternatively the size at maturity $\left(S_{A}\right)$ could be constant. In this case the time it would take an animal to reach reproductive maturity would depend on the same two life history characteristics. Both of these viewpoints are considered in our discussion of optimal life history strategies (see below).

The system of differential equations described above consists of four vectors: $N, B s, B t$ and $B e$. Partial derivatives are used because these four unknowns and the assimilation and mortality constructs are functions of more than one variable. Number of animals, for example, is a function of age, time, and even structural biomass (eqn 13). Similarly all biomass vectors are functions of age and time. The mortality and assimilation functions are dependent on biomass and therefore they are functions of age and time also. The existence of so many implicit functions dissuaded us from seeking analytical solutions to the equations. Instead we obtained numerical solutions by first generating an initial size distribution using the size of newly-hatched animals $\left(E\left(1-R_{e}\right)^{D_{e}}\right)$ and their rates of growth $A$ (eqn 6). For the steady-state solutions we report here, we next computed fecundities and survivorships for animals in each age class from their size and reproductive schedule (see 'Mortality functions' below and Table 1). These age-specific fecundities and survivorships are fixed constants under steady-state conditions and may be used to obtain the population's growth rate $r$ and stable age distribution (Leslie, 1948; also see below).

\section{Mortality functions}

Mortality resulting from predation is a powerful selective force in zooplankton communities (Brooks \& Dodson, 1965). The selection is sizespecific; different sizes of prey offered to fish elicit different predation rates (Werner \& Hall, 1974; Confer \& Blades, 1975). Based on visual cues, their predatory response depends not only on actual size of the prey item but also on proximity of the prey to the fish (O'Brien, Slade \& Vinyard, 1976). Alternative selection criteria may be important as well, such as enhanced visibility of the prey by increased body pigmentation (Zaret \& Kerfoot, 1975; Hairston, 1979) and characteristic prey movements (Zaret, 1980). All empirical evidence, however, emphasizes the vertebrate predator's use of sight to distinguish individual prey items.

Invertebate predators, on the other hand, rely on tactile cues to locate their prey (Strickler, 1975; Pastorok, 1980). These predators exhibit selection on the basis of body size, but they prefer small animals to larger prey primarily because of the relative ease of handling a smaller prey item (Fryer, 1957; Brandl \& Fernando, 1974; Kerfoot, 1977).

We therefore make the mortality function, $m$ (eqns 3 and 4 ) dependent on animal size. Note that $m$ is an age-specific mortality to the extent that size and age are interconvertible. Figure 3 illustrates the general mortality function we use. The probability of death for any animal depends on two types of predation pressure called 'vertebrate' and 'invertebrate' predation. The former implies selective predation on large prey; 


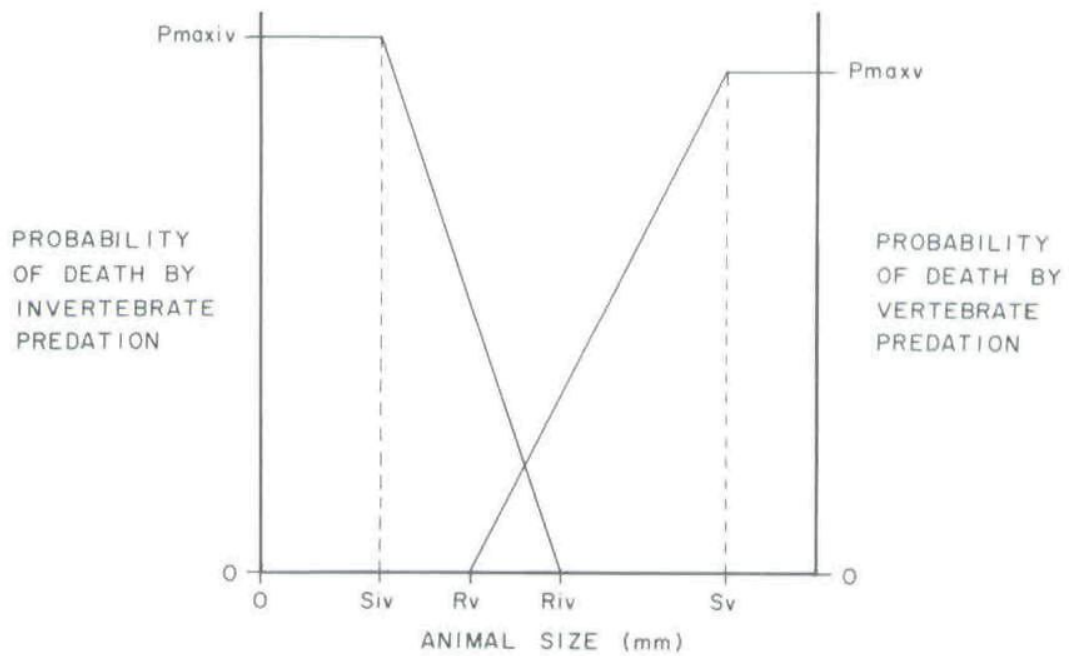

FIG. 3. Mortality by predation as a function of animal size. Pmaxiv is the maximum probability of death by invertebrate predation. Pmaxv is the maximum probability of death by vertebrate predation. See Table 1 for definitions of Siv, Riv, Sv and $R v$.

the latter implies a preference for smaller prey. Linear constructs are used because there is evidence for linear increases and decreases of vertebrate (Confer \& Blades, 1975) and invertebrate (Pastorok, 1980) predation, respectively, with increases in prey size. Moreover these simple constructs contain parameters that have some biological foundation. $R v$, for instance, corresponds to the smallest apparent prey size that a vertebrate sighted-predator can detect or respond to. Below this size mortality from vertebrate predation is zero. Above this size the probability of death per unit time from attack by a vertebrate predator increase linearly up to some critical size $(S v)$ above which the probability of death is a constant value (Pmaxv) for all size classes. An analogous set of parameters (Riv, Siv, Pmaxiv) defines the extent of mortality by invertebrate predators, except invertebrate predation acts on smaller animals in accordance with empirical evidence. Changing these six parameters allows us to simulate different degrees of invertebrate and vertebrate predation (Table 1).

\section{Stable age distribution}

For all simulations presented here we assume that the zooplankton population is in a constant, steady-state environment. This assumption is consistent with formulations presented for the rates of assimilation and egg respiration and excretion, which hold for constant temperature and food concentration. Under steady-state conditions in which age-specific mortality and fecundity are fixed, the population tends toward a stable age distribution (Lotka, 1925). It is appropriate then to calculate the population's intrinsic rate of increase or per capita growth rate, $r$. Using the age-specific mortality function and age-specific fecundity data from the model, we obtained values of survivorship and fecundity to place in the elements of a Leslie (1948) projection matrix. The populations's per capita growth rate, $r$, is computed from the equation $\lambda=e^{r \Delta t}$ where $\lambda$ is the single positive real root of the characteristic polynomial of the projection matrix. We then compute the stable age distribution from the life history characteristics and $\lambda$ (Leslie, 1948).

The assumption of a steady state environment might at first appear unrealistic to those unfamiliar with zooplankton populations in continuous culture. Seasonal variation in temperature, food supply, and other important environmental conditions is a fact of nature. We regard the investigation of zooplankton population dynamics under steady state conditions as a necessary preamble to the transient case. We will show that our results conform to some generally accepted hypotheses concerning the evolution of life history strategies. Under the conditions we 
specify, density-dependent effects are irrelevant. Elsewhere we will describe how changes in population size can influence food abundance and thereby alter assimilation and growth. For now we adhere to the features of continuous cultures, where despite positive net growth rates, populations remain steady and in balance with their food.

\section{Results}

\section{Determining the number of age classes}

Our numerical solutions involve approximating the continuous age-density distribution of Fig. 1 by an arbitrary number of age classes. Obviously the smaller the age interval or equivalently, the larger the number of age classes, the closer is the approximation. To determine the minimum number of age classes necessary to approximate the continuous distribution, we used the value of $r$ as a criterion. Because $r$ is a function of survivorship and fecundity, life history characteristics such as egg development time and mean lifespan become important when we wish to compare one value of $r$ with another. Thus when we compare the values of $r$ for two populations, all life history traits are identical for the populations unless otherwise indicated.

In Fig. 4, $r$ is plotted against the number of age classes per day for three different mortality regimes: no predation, vertebrate predation and invertebrate predation. Beginning with one age class per day, growth rates oscillate irregularly about asymptotic values. The oscillation is

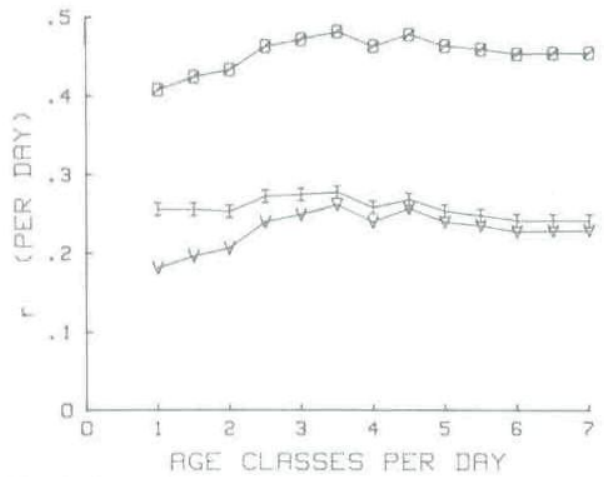

FIG. 4. Intrinsic rate of increase against the number of age classes per day for populations under three different mortality regimes. 0 , No predation; V. vertebrate predation; $I$, invertebrate predation. damped, however, and at approximately seven age classes per day values of $r$ are stable and close to the value that would be obtained using an infinite number of age classes. In order to approximate the continuous age-density distributions, we therefore use seven age classes per day in all subsequent simulations to allow for unbiased estimation of $r$.

\section{Life history strategies}

We investigated next how intrinsic rates of population increase depended on several life history characteristics. For different mortality regimes, we computed $r$ for a variety of egg sizes and ages or sizes at first reproduction, and thereby systematically investigated threedimensional fitness surfaces. The global maximum for any fitness surface corresponds to the reproductive strategy that confers an adaptive advantage to the zooplankter. This approach has been used previously by Cole (1954), Lewontin (1965) and Meats (1971) to examine the relative importance of age at first reproduction, age at last reproduction, clutch size, and other life history parameters to maximizing a population's intrinsic rate of increase.

Figure $5 \mathrm{~A}$ is a surface generated using no mortality to the population. The global maximum (shaded region at an egg size of $0.2 \mu \mathrm{gC}$ and ages at maturity of $3-4$ days) represents a trivial solution: in the absence of predation, animals should produce very small eggs and begin reproduction almost immediately. This result agrees with the generally accepted hypothesis that in a growing population natural selection will force age at first reproduction to a physiological minimum (Cole, 1954; Lewontin, 1965). Animals hatching from small but finite eggs require a short period of time, predetermined by the assimilation rate, before their reproductive biomass permits enough eggs to maximize the population's growth rate. Postponing reproductive maturity any further results in lower reproductive output and thus lower growth rates for the population. Notice that for any particular age at maturity the population's growth rate is largest for small eggs and smaller for large eggs. Small egg size corresponds to a large number of newborn (eqn 13); so the selective advantage conferred upon animals with lower ages at first reproduction is greater for animals with large clutches than for 
m

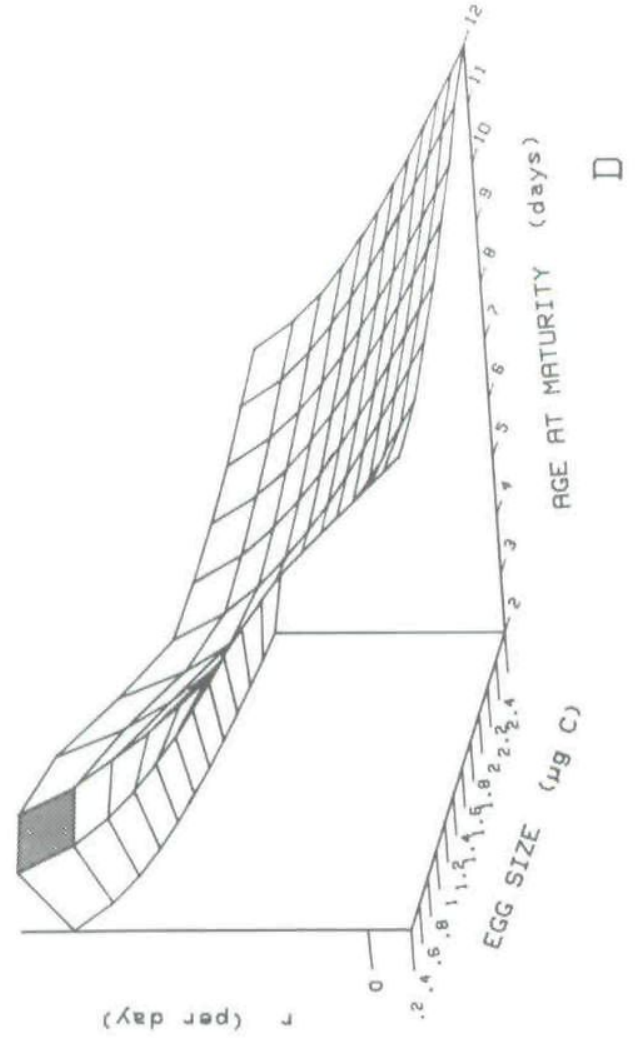

匹.

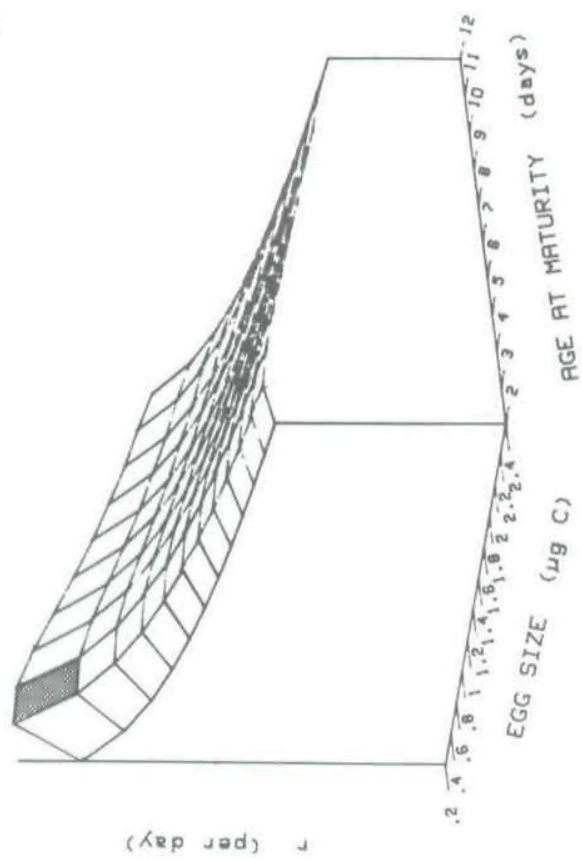

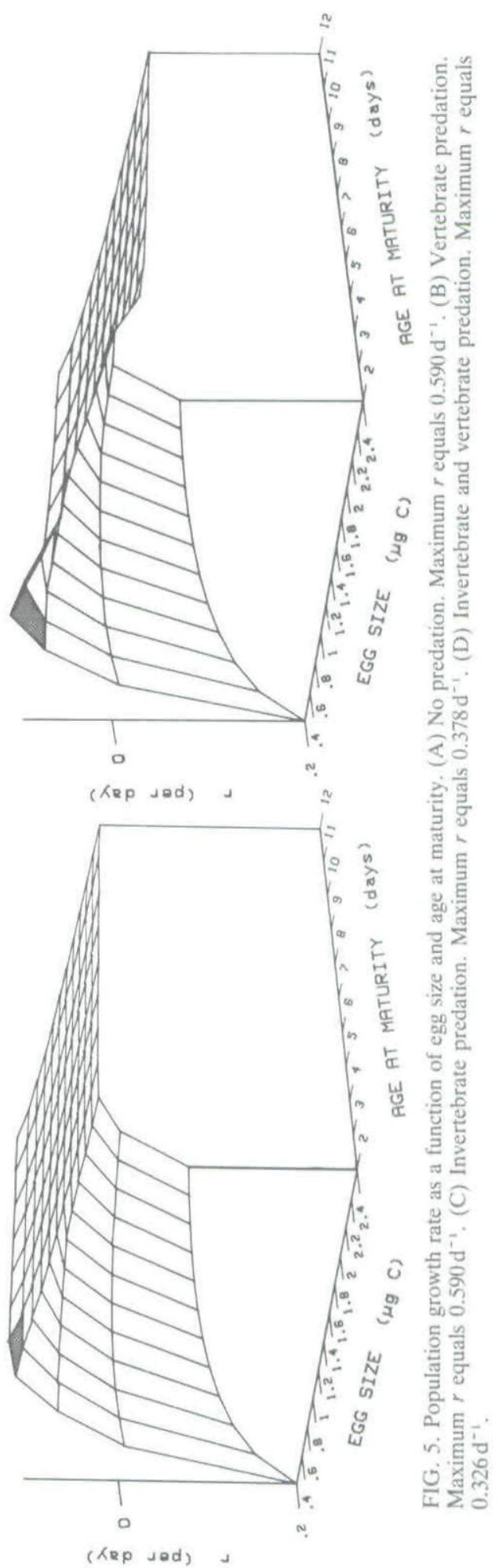



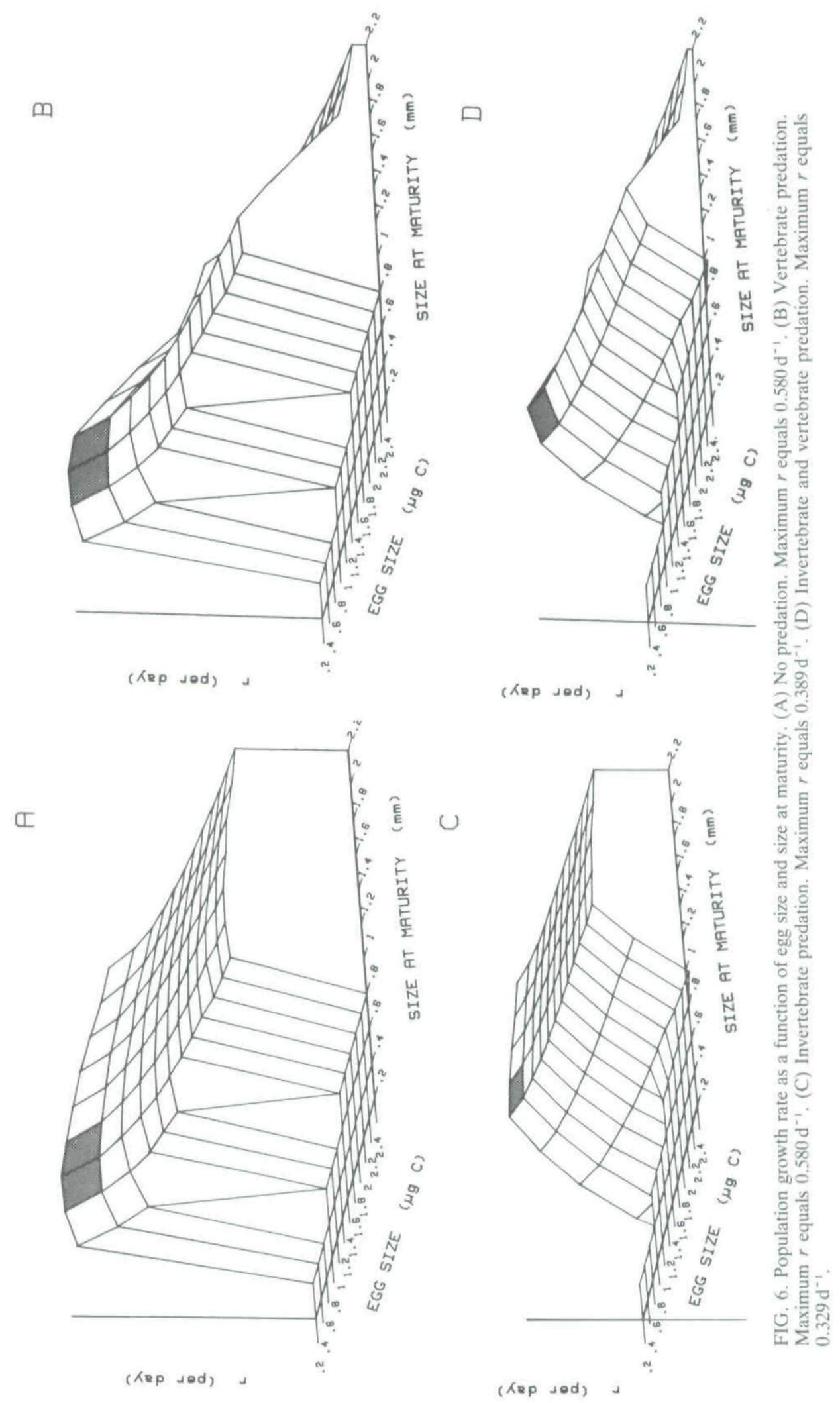
those with small ones (Cole, 1954). Computing population growth rates for different sizes at maturity yields a similar fitness surface (Fig. 6A). The global maximum $r$ is achieved by animals that brood small eggs and mature rapidly enough to become adults at a relatively small size.

Fitness surfaces under vertebrate predation (Fig. 5B) are qualitatively very similar to the case of no predation. The only difference is lower $r$ values for populations arising from large eggs and taking more than 3 days to reach adulthood. This stems from the size-specific mortality imposed on the larger animals. Those that mature at a relatively small size escape predation by vertebrate planktivores (Fig. 6B). However, animals that reach adulthood at sizes greater than $1.2 \mathrm{~mm}$, the smallest size our model vertebrate predator can detect, become targets for these predators, and the reduction in adult survivorship leads to lower population growth rates.

Fitness surfaces created under invertebrate predation have a different appearance. Highest population growth rates occur at small egg sizes and intermediate sizes at first reproduction (Fig. 6C). Predation is most intense on smaller individuals, but population growth rates are maximal at small egg sizes. Juveniles hatching from large eggs are less susceptible to invertebrate predators than those hatching from small eggs. The increase in juvenile survivorship is not, however, large enough to offset the reductions in fecundity that accompany increases in egg size, and population growth rates necessarily decline with increases in egg size. The optimal size at maturity is also the result of two opposing selective forces. When animals mature within the size range available to invertebrate predators, sizes less than $1.4 \mathrm{~mm}$ in Fig. $6 \mathrm{C}, r$ increases with size at first reproduction because adult mortality decreases. Above this size, however, there is no advantage to being larger, and postponing reproductive maturity lowers population growth rate by reducing the time that animals spend as egg-bearing adults. Expressed as a function of age at first reproduction (Fig. 5C), maximum population growth rate occurs for small egg sizes and intermediate ages at first reproduction. In this case, an increase in egg size increases the size at maturity. Animals with fixed reproductive schedules can increase their numbers most quickly if they lay large eggs that develop into adults large enough to escape invertebrate predation. Once adults exceed the range of sizes available to invertebrate predators, further increases in egg size can only reduce the population growth rate by reducing clutch size. This is most clearly illustrated in Fig. $5 \mathrm{C}$ for animals that take longer than 4 days to mature. Adults of these populations are larger than $1.4 \mathrm{~mm}$, the maximum size available to an invertebrate predator, and population growth rates decline with increases in egg size because of the reduction in clutch size.

So far we have examined cases in which vertebrate and invertebrate predation operate separately. Figures $5 \mathrm{D}$ and $6 \mathrm{D}$ illustrate fitness surfaces created for populations exposed simultaneously to invertebrate and vertebrate predators. The optimal strategy for an animal is to lay small eggs and postpone adulthood until it grows to the size that offers the largest chance of survival.

For all the simulation results presented thus far, animals were specified to put $100 \%$ of their net assimilate into reproduction upon reaching adulthood. In well-fed populations of Daphnia pulex, Richman (1958) estimated that approximately $95 \%$ of all energy in excess of maintenance requirements is expended on egg production; the remainder is used for growth. We ask next how the global maxima of the fitness surfaces respond to reductions in net assimilate that is allocated to reproduction. Can the population's growth rate, $r$, be increased by allocating less than $100 \%$ of the available energy to reproduction?

For populations whose only source of mortality is natural death by old age, the intuitive answer to this question is 'no' because it would seem best for an organism to put all of its assimilated resources into reproduction and thereby produce more eggs. Inspection of Table 2 , however, illustrates that certain life history strategies permit small increases in $r$ when less than $100 \%$ of assimilate is allocated to reproduction. In Fig. 7 we examine the underlying mechanisms for these increases in $r$ using animals that hatch from $1 \mu \mathrm{gC}$ eggs and reach maturity at $1 \mathrm{~mm}$ as an example.

Putting some of their resources into growth allows adults to grow beyond $1 \mathrm{~mm}$, the size at first reproduction; because net assimilation rate depends on animal size (eqn 6), more total biomass can be acquired subsequently. Although only a portion of this total is put into 
TABLE 2. Effect on $r$ of allocation of reproductive effort in the absence of predation. Maximum $r$ for each size at maturity is in italics. All animals hatch from $1 \mu \mathrm{g} \mathrm{C}$ eggs.

\begin{tabular}{lllll}
\hline & \multicolumn{5}{l}{$\begin{array}{l}\text { Calculated } r \text { for different } \% \text { assimilate } \\
\text { alocated to reproduction }\end{array}$} \\
\cline { 2 - 5 } $\begin{array}{l}\text { Size at } \\
\text { maturity }(\mathrm{mm})\end{array}$ & 100 & 90 & 80 & 70 \\
\hline 0.8 & 0.395 & 0.403 & 0.405 & 0.403 \\
1.0 & 0.404 & 0.405 & 0.403 & 0.396 \\
1.2 & 0.402 & 0.399 & 0.394 & 0.385 \\
1.4 & 0.393 & 0.388 & 0.381 & 0.371 \\
\hline
\end{tabular}

egg production, this strategy results in larger clutches for non-primiparous adults than could be achieved by termination of growth at maturity (Fig. 7A). The values of these clutches in determining $r$, however, are much less than that of the
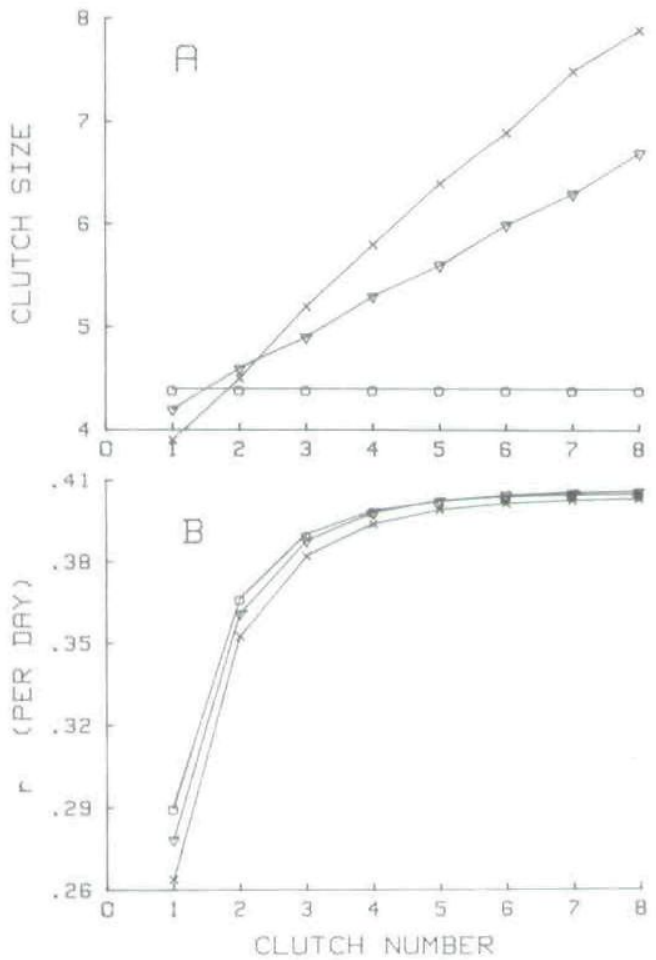

FIG. 7.Variables that influence population growth rate as a function of clutch number for animals that allocate $100 \%(0), 90 \%(\nabla)$ and $80 \%(\times)$ of their net assimilate to reproduction. Clutch size of individuals allocating less than $100 \%$ of net assimilate to reproduction is able to increase over a number of clutches because their body size increases with age. (A) Size of $i$ th clutch. (B) Population growth rate achieved by hatching $i$ clutches. first brood hatched. Population growth rates can therefore be increased above that for animals with uniform fecundities (i.e. $100 \%$ allocation of energy to reproduction) if two conditions exist: (1) the clutch size of primiparous females cannot be significantly lower than that of animals in populations with uniform fecundities, and (2) animals must live long enough to hatch several large clutches whose collective contribution to $r$ offsets the negative effects on $r$ produced by the reduced clutch size of primiparous females. If animals live only long enough to hatch one brood, it is best for them to put all of their assimilate into reproduction and produce as many eggs as possible because growth rate is determined only by fecundity of primiparous females (Fig. 7B). Animals that live long enough to hatch several clutches, on the other hand, may compensate for a small initial clutch by continuing to grow and by producing larger clutches that their increased size and physiology permit. Progressive reduction in per cent allocation to reproduction eventually lowers the fecundity of primiparous females to such an extent that its negative effect on $r$ cannot be outweighed by batching a greater number of clutches. Because of their physiology, clutch size in these animals increases less than linearly with age. Clutch size would have to increase with age exponentially to compensate indefinitely for the smaller contribution that nonprimiparous clutches make to $r$.

We can now explain why $r$ decreases with some life history strategies and increases with others as the percentage allocation is reduced (Table 2). At constant egg size a reduction in size at maturity corresponds to a reduction in age at maturity as long as all animals assimilate biomass according to the same pattern. By reducing age at maturity animals hatch more clutches and also 
increase the value that their first clutch makes to $r$. Increases in $r$ with reductions in per cent allocation to reproduction are therefore observed only for animals that mature at smaller sizes. Unlike animals that begin to reproduce at larger sizes, these animals mature earlier and hatch more non-primiparous clutches that collectively increase $r$.

Instead of fixed egg size, consider next the case in which size at maturity is held constant. Then, age at first reproduction can be reduced by increasing egg size. An increase in egg size, however, corresponds to lower fecundities for all females, because they carry fewer, larger eggs. That tradeoff is disadvantageous in terms of population growth rates. Therefore as the allocation to reproduction is reduced below $100 \%$ the maximum $r$ occurs at the minimum egg size $(0.2 \mu \mathrm{gC})$ but at progressively smaller sizes at maturity until a minimum size is reached that depends on the size of the egg (Fig. 8).

Determining the optimal allocation of reproductive effort for animals exposed to sizespecific predation is more complex because the size structure of the population changes with the percentage of assimilate allocated to growth. Adults continue to grow after the onset of maturity and the larger clutches hatched by older adults result in a higher proportion of juveniles in the population. Growth rates are maximized for populations exposed to vertebrate predation when animals hatch from small eggs and mature quickly at a small size (Figs. 5B and 6B). This strategy has placed animals below the range of our model vertebrate predator. Therefore as the allocation to reproduction is reduced below $100 \%$ the global maximum $r$ follows the same pattern as that for populations without predation (Fig. 8).

Populations exposed to invertebrate predators have higher growth rates when animals hatch from small eggs and become mature at sizes

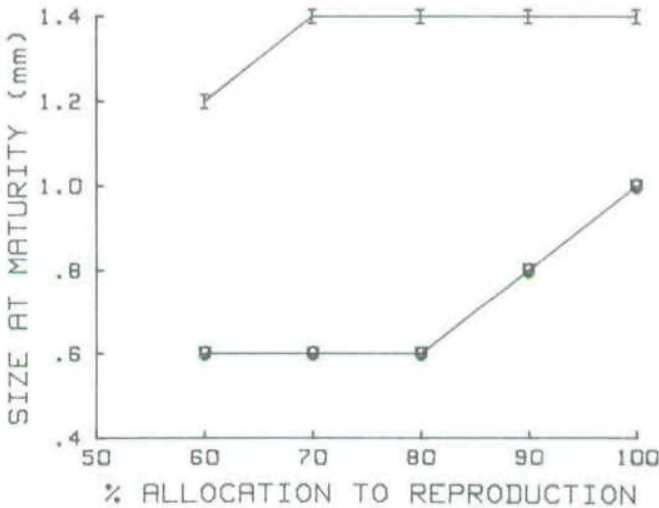

FIG. 8. Sizes at maturity that yield highest population growth rates given a particular per cent allocation of net assimilate to reproduction. All animals hatch from $0.2 \mu \mathrm{g} \mathrm{C}$ eggs. 0 , No predation; $\mathrm{V}$, vertebrate predation; I, invertebrate predation.

beyond the range available to our model invertebrate predator (Fig. 6C). Reducing the percentage of assimilate allocated to reproduction, however, favours smaller sizes at maturity. Figure 8 shows that high mortality on animals less than $1.4 \mathrm{~mm}$ has a greater influence on the global maximum $r$ than do the benefits accrued by hatching more large clutches, and $1.4 \mathrm{~mm}$ is the optimum size at maturity for all but one percentage allocation to reproduction.

Those life histories that permit increases in $r$ with reductions in the percentage of assimilate allocated to reproduction require that animals hatch several clutches by reducing their age at first reproduction. One additional way this could be accomplished is by increased rates of assimilation for animals developing from a fixed egg size. We computed $r$ for different percent allocations of reproductive effort at three different food levels (Table 3 ). Food level may be changed by varying the coefficient $a$ in eqn 6 . When food levels are relatively low, $r$ is maximized by

TABLE 3. Allocation of reproductive effort in the absence of predation as a function of food level. Maximum $r$ for each food level is in italics. Animals hatch from $1.0 \mu \mathrm{gC}$ eggs and reach maturity at $1.0 \mathrm{~mm}$.

\begin{tabular}{lllll}
\hline \multirow{2}{*}{$\begin{array}{l}\text { Relative } \\
\text { food level }\end{array}$} & \multicolumn{4}{c}{$\%$ assimilate allocated to reproduction } \\
\cline { 2 - 5 } & 100 & 90 & 80 & 70 \\
\hline 0.9 & 0.126 & 0.116 & 0.105 & 0.093 \\
1.8 & 0.404 & 0.405 & 0.403 & 0.396 \\
3.6 & 0.614 & 0.639 & 0.655 & 0.663 \\
\hline
\end{tabular}


putting $100 \%$ of net assimilate into egg production. As food levels increase, animals may allocate less to reproduction and increase population growth rates because they are able to assimilate and grow more quickly, reach their size at maturity at an earlier age, and thereby hatch a greater number of larger clutches.

\section{Comparison with previous studies}

The trends in population growth rates predicted by our model for animals with different sizes of eggs and sizes at maturity are similar to those of another model of zooplankton population growth (Lynch, 1980b). The predictions are supported by several independent observations of zooplankton communities (cited in Lynch, 1980b). Our calculations, however, have pointed out an alternative life history strategy that zooplankton could adopt when exposed to invertebrate predators that prefer small prey. One method of escaping these predators, as discussed by Lynch (1980b), is for animals to hatch from large eggs into newborn that are beyond the size range available to the predators and then begin reproduction very quickly (cf. Fig. 5C). Another strategy that leads to even larger growth rates is for animals to hatch from small eggs and allocate $100 \%$ of their net assimilate to growth until they grow outside the size range available to invertebrate predators (Figs. 5C and 6C). The increase in juvenile mortality that results from the small size of offspring is not enough to outweigh the benefits derived from increased adult survivorship and fecundity. This strategy is, of course, applicable only to populations whose own growth does not cause corresponding increases in predator density. This provision requires restrictions on the predator population or long generation times for the predator relative to its prey.

In another paper, Lynch (1980a) provides an extensive compilation of published life history traits for well-fed laboratory populations of cladocerans. Many of the species that mature at relatively small sizes continue to grow after primiparity and hatch progressively larger clutches as they get older (cf. Lynch's Fig. 5). Large species, on the other hand, stop growing once they reach maturity and produce clutches of uniform sizes. These data imply that the cladocerans maturing at small sizes are allocating larger percentages of their resources after maturity to growth than animals which begin reproduction at larger sizes (Fig. 7; Lynch's Fig. 1f). Our model predicts these patterns of age-specific growth and reproduction as natural consequences of selective forces working to maximize the intrinsic rates of increase of these populations. We predict that animals which mature at small sizes are able to increase $r$ by allocating less than $100 \%$ of their resources to reproduction, whereas those that begin reproducing at larger sizes cannot (Table 2).

Robertson \& Salt (1981) recently examined the effect of food level on life history traits for populations of Asplanchna girodi, a planktonic rotifer. Animals raised on higher food levels had significantly higher net reproductive rates $R_{0}$, which are directly related to population growth rate $r$ by $R_{0}=e^{r T}$ in which $T$ equals mean lifespan. The increase in $R_{0}$ with greater amounts of food resulted from an increase in fecundity, a decrease in age at first reproduction, and a smaller time interval between births (or egg development time). These trends imply that increases in food allowed these rotifers to maximize $r$ by hatching a greater number of larger clutches. This is precisely the mechanism for optimal allocation of reproductive effort that is predicted by our model. Rotifers raised on higher food levels became reproductively mature at substantially lower pecentages of their maximum sizes (Fig. 11, Robertson \& Salt, 1981); this means that they were allocating less than $100 \%$ of their energy to reproduction, continuing to grow after reaching maturity, and still achieving higher population growth rates. Although the results are consistent with our predictions concerning optimal allocation of reproductive effort as a function of food level (Table 3), their study illustrates an important point. To analyse the effect of egg size, age and size at maturity, per cent allocation to reproduction, or any other important demographic variable on $r$, we kept other variables such as lifespan and egg development time constant. In nature, these variables are subject to selective forces that operate on them simultaneously for any particular mortality regime or food level.

\section{Applications to egg ratio models}

Several presently used models attempt to estimate per capita birth and death rates for zooplankton populations. Edmondson

(1960) 
suggested that the ratio of eggs per female might be used to calculate a finite daily hatching rate. This proposal laid the foundation for several other models of zooplankton population growth, each using the egg ratio but relying on different assumptions (see Seitz, 1979, for a review). These models are only as good as the assumptions behind them, and there have been surprisingly few attempts to investigate the biases introduced by their assumptions (Taylor \& Slatkin, 1981). Using our model, we will show the consequences of age-specific recruitment and mortality to any analysis of zooplankton populations and present a method to compute unbiased birth and death rates from field data.

Edmondson's (1960) initial approach was straightforward. Some of the eggs present in a population hatch into newborn each day. Once that number is known, per capita birth rates can be estimated by a number of means. The difficulty arises in trying to determine the fraction of eggs that will hatch during any period of time. Determination of this fraction of eggs from field samples is hindered by two sources of bias. First, the age distribution of eggs may be nonuniform, especially when the population's rate of increase is not zero. Increasing populations will characteristically be dominated by young eggs. Previous models have often made incorrect, simplifying assumptions about the egg age distribution, but Threlkeld (1979) has now shown how to establish the age distribution of Daphnia eggs on a morphological basis. A second bias arises from predation on ovigerous females. Even if the fraction of eggs that can potentially hatch during a sampling interval is known, some of these eggs may not survive. Threlkeld's (1979) estimate of the number of eggs that hatch into newborn does not consider egg mortality during the sampling interval and is therefore an overestimate of actual recruitment.

Our unbiased estimate of per capita birth rate is derived from formulations implicit to populations with stable age distributions. The stable age vector $\bar{N}$ is defined uniquely (within an arbitrary scaling constant) by a finite rate of increase $\lambda=e^{r \Delta t}$ and a set of age-specific fecundities and survivorship probabilities that comprise a matrix $A$ such that $A \bar{N}=\lambda \bar{N}$ (Leslie, 1948). Therefore certain relationships exist among the elements of $\bar{N}$ that are characteristic of stable age distributions. In particular

$$
N(a+\Delta a)=N(a) e^{-r \Delta a} \cdot p(a)^{\Delta a}
$$

where $p(a)^{\Delta a}$ is the probability that animals of age $a$ survive to age $a+\Delta a$. If adults of different ages experience similar probabilities of survival, a similar equation applies to their eggs:

$$
\epsilon(\hat{a}+\Delta a)=\epsilon(\hat{a}) \cdot e^{-r \Delta a} p^{\Delta a}
$$

where $\epsilon(\hat{a})$ equals the number of eggs of age $\hat{a}$, $p^{\Delta a}$ is the probability that eggs will survive to become $\Delta a$ days older, and $r$ is the intrinsic growth rate of the population. By regarding egg age as a continuous variable that ranges from $a=0$ to $a=D$, eqn (15) can be rewritten as

$$
\epsilon(\hat{a})=\epsilon(0) e^{\hat{d} \cdot s}
$$

or as

$$
\ln \epsilon(\hat{a})=\ln \epsilon(0)+\hat{a} \cdot s
$$

where $\epsilon(0)$ is the number of eggs of age 0 (just laid), and $s=\ln (p)-r$. A line regression of $\ln \epsilon(\hat{a})$ on $\hat{a}$ should yield $s=(\ln p)-r$ as the slope.

Using our model to generate egg age distributions, we predicted survival probabilities for eggs exposed to different mortality schedules by using eqn (17). We compared the predictions with the survivorshps that we imposed on the adults carrying the eggs (Fig. 9, Table 4). With no mortality (probability of survival equals one for all animals), the slope equals $-r$ (Fig. 9). The other examples listed in Table 4 also illustrate the unbiased prediction of egg survivorship by eqn (17).

We use this information to derive a simple and accurate estimate of egg hatching rates. From

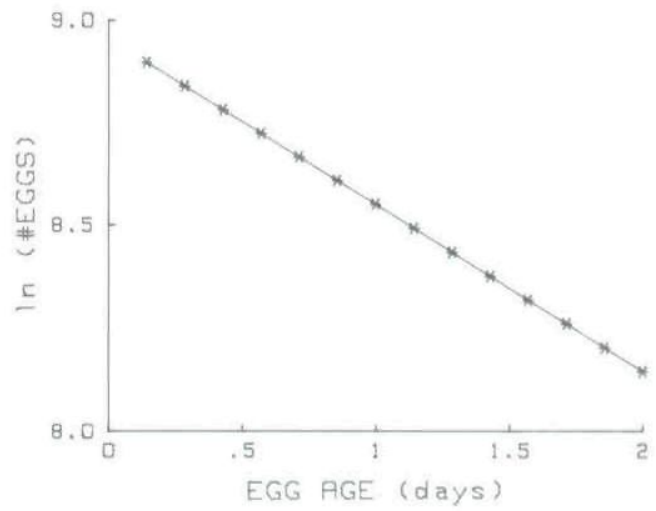

FIG. 9. Semi-log plot of the egg age distribution of a population without predators. Linear regression yields a slope of -0.404 , and the population's rate of growth equals 0.404 . 
TABLE 4. Predictions of egg survival probabilities based on best fits of egg age distributions to eqn (17)

\begin{tabular}{llll}
\hline $\begin{array}{l}\text { Mortality schedule } \\
\text { (age-specific survivorship } \\
\text { in parentheses) }\end{array}$ & $\begin{array}{l}\text { Population } \\
\text { growth rate, } \\
r\left(\mathrm{~d}^{-1}\right)\end{array}$ & $\begin{array}{l}\text { Actual egg } \\
\text { survival } \\
\text { probability }\end{array}$ & $\begin{array}{l}\text { Predicted egg } \\
\text { survival } \\
\text { probability }\end{array}$ \\
\hline No mortality $(p=1)$ & 0.404 & 1.00 & 1.00 \\
Uniform mortality $(p=0.75)$ on all animals & 0.123 & 0.75 & 0.75 \\
Low mortality $(p=0.75)$ on adults only & 0.160 & 0.75 & 0.75 \\
High mortality $(p=0.25)$ on adults only & -0.761 & 0.25 & 0.25 \\
Low mortality $(p=0.5)$ on juveniles only & 0.319 & 1.00 & 1.00 \\
High mortality $(p=0.01)$ on juveniles only & -0.030 & 1.00 & 1.00 \\
\hline
\end{tabular}

eqn (16), the number of eggs of age $D$ at time $t$ is

$$
\epsilon(D, t)=\epsilon(0, t) e^{D \cdot s}
$$

where, because the population is in exponential growth,

$$
\epsilon(0, t)=\epsilon(0,0) e^{r t}
$$

By integrating eqn 18 from $t=0$ to $t=\Delta t$ we get the number of eggs that hatch during the interval which divided by total population abundance at $t=0\left(N_{0}\right)$ is

$$
\beta=\frac{\epsilon(0,0) e^{D s}\left(e^{r \Delta t}-1\right)}{N_{0} \cdot r}
$$

The total number of eggs at $t=0\left(\epsilon_{0}\right)$ is the integral of eqn (16) from $\hat{a}=0$ to $\hat{a}=D$ :

$$
\epsilon_{0}=\frac{\epsilon(0,0)\left(e^{D s}-1\right)}{s}
$$

From eqns 20 and 21 ,

$$
\beta=\frac{\epsilon_{0}}{N_{0}} \cdot \frac{s}{\left(1-e^{-D s}\right)} \cdot \frac{\left(e^{r \Delta t}-1\right)}{r}
$$

where $\beta$ is the parameter required by Leslie's (1948) expression for birth rate $\left(b\right.$, day $\left.^{-1}\right)$ :

$$
b=\frac{r \beta}{\left(e^{r \Delta t}-1\right)}
$$

Thus,

$$
b=\frac{\epsilon_{0} s}{N_{0}\left(1-e^{-D s}\right)}
$$

is our estimate of birth rate based on the egg ratio $\left(\epsilon_{\mathrm{o}} / N_{\mathrm{o}}\right)$, egg development time $(D)$ and the eggage distribution. An identical equation can be derived from equations presented by Seitz (1979) by using his eqns (5), (15) and (18) and letting $\ln (p)=-d_{E}$ in his terminology. A similar equation appears in Lynch (1982: eqn 7). Lynch (1982) incorrectly claims that his model does not require a stable age distribution. Even though he presumes that each age class can change independently at exponential rates $r\left(a_{j}\right)$, the realistic interdependence of age and time (eqn 4) guarantees that such populations have stable age distributions and that all $r\left(a_{i}\right)$ are equal.

Equation (24) gives correct birth rate estimates when checked against our model regardless of whether mortality occurs on juveniles alone, adults alone, or on both. The same is not true of other equations commonly used (Edmondson, 1960; Caswell, 1972; Paloheimo, 1974). The models presented by all three of these authors systematically overestimate the birth rates of populations exposed to predation on adults. The errors increase with the magnitude of adult mortality. When predation is confined to juveniles, Paloheimo's (1974) model underestimates $b$ with a bias that increases with mortality rates. The other two models (Edmondson, 1960; Caswell, 1972) either overestimate or underestimate $b$ depending on the magnitude of mortality. The differences result from changes in age-structure within the population. The directions and magnitudes of biases associated with these various models are illustrated in Fig. 10.

There is at least one more consequence of assessing the slope $(s)$ from a regression involving the age distribution of eggs (eqn 17). Combined with the empirical population growth rate,

$$
r=\frac{\ln \left(N_{\Delta t} / N_{0}\right)}{\Delta t}
$$

it provides the information needed to assess agespecific mortality rates. Using eqns (24) and (25) we can calculate a per capita death rate for the entire population $(d=b-r)$, but that does not 

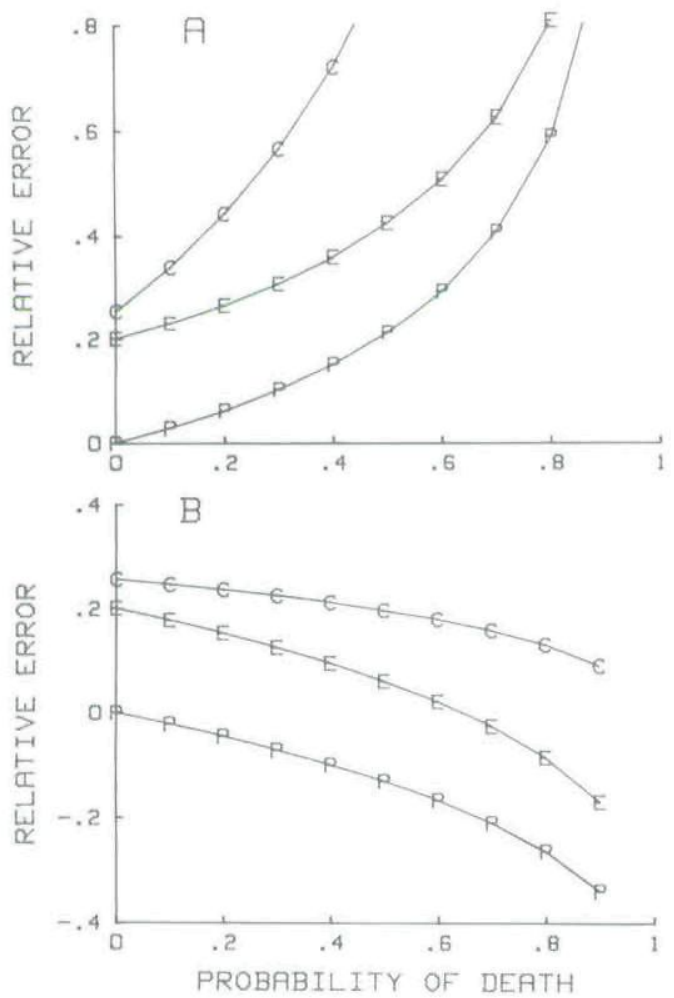

FIG, 10. Relative error in predictions of per capita birth rate based on Edmondson's (E), Caswell's (C) and Paloheimo's (P) method as a function of mortality. (A) Uniform mortality on adults only. (B) Uniform mortality on juveniles only.

mean that the mortality is uniform with age. Indeed, the rate of mortality calculated that way may have no direct physical analogue, in the sense that there may be no set of animals dying at that rate in the population. To understand where the mortality is concentrated, it is necessary to consider the magnitude of the regression slope, $s$ (eqn 17). When $s=-r$, there is no mortality on adults. When $s=-b$, mortality is uniform among juveniles and adults. As the magnitude of mortality rates on adults exceeds that of juveniles, $s<-b$.

Implicit to derivation of eqn (17) is that all adults carrying eggs experience equal probabilities of death. Because size-selective predation is common in zooplankton communities (Brooks \& Dodson, 1965; Dodson, 1974; Kerfoot, 1977), adults of different sizes may experience different mortalities. Therefore it is most appropriate to use eqn (17) with egg age distributions of similar sized adults. For species in which adults range considerably in size, separate analyses by size class could provide concise estimates of sizespecific mortality.

This method of calculating birth rates for zooplankton populations has a theoretical foundation and can be used with information available from field samples. Here we have assumed that the population's age distribution is stable. This assumption cannot apply during transient phenomena such as sudden reductions in the rate of egg production per adult, which might arise during food limitation and skew the egg age distribution unpredictably (Threlkeld, 1979). The consequences of non-steady states for zooplankton models are the subject of our continuing research.

\section{Acknowledgments}

We thank Donald Scavia for his helpful suggestions during the formulation of the model and for reviewing an earlier version of this manuscript. We also benefited from helpful discussions with John Korstad and Paul Rago.

This study was supported by NOAA Contract NA79RAC00120.

\section{References}

Allan J.D. \& Goulden C.E. (1980) Some aspects of reproductive variation among freshwater zooplankton. American Society of Limnology and Oceanography Special Symposium, 3, 388-410.

Argentesi F., de Bernardi R. \& di Cola G. (1974) Mathematical models for the analysis of populations dynamics in species with continuous recruitment. Instituto Italiano di Idrobiologia: Memorie, 31, 245-275.

Boraas M.E. (1980) A chemostat system for the study of rotifer-algal-nitrate interactions. American Society of Limnology and Oceanography Special Symposium, 3, 173-182.

Bottrell H.H., Duncan A., Gliwicz Z.M., Grygierek E., Herzig A., Hillbricht-Ilkowska A., Kurasawa H., Larsson P. \& Weglenska T. (1976) A review of some problems in zooplankton production studies. Norwegian Journal of Zoology, 24, 419-456.

Brandl Z. \& Fernando C.H. (1974) Feeding of the copepod Acanthocyclops vernalis on the cladoceran Ceriodaphnia reticulata under laboratory conditions. Canadian Journal of Zoology, 52, 99-105. 
Brooks J.L. \& Dodson S.I. (1965) Predation, body size, and composition of plankton. Science, 150, 28-35.

Caswell H. (1972) On instantaneous and finite birth rates. Limnology and Oceanography, 17, 787-791.

Cole L.C. (1954) The population consequences of life history phenomena. Quarterly Review of Biology, 29, 103-137.

Collins C.D. (1980) Formulation and variation of a mathematical model of phytoplankton growth. Ecology, 61, 639-649.

Confer J.C. \& Blades P.I. (1975) Omnivorous zooplankton and planktivorous fish. Limnology and Oceanography, 28, 571-579.

Dodson S.I. (1974) Zooplankton competition and predation: an experimental test of the sizeefficiency hypothesis, Ecology, 55, 605-613.

Droop M.R. (1973) Some thoughts on nutrient limitation in algae. Journal of Phycology, 9, 264-272.

Dumont H.J., Van de Velde I. \& Dumont S. (1975) The dry weight estimate of biomass in a selection of Cladocera, Copepoda, and Rotifera from the plankton, periphyton, and benthos of continental waters. Oecologia, 19, 75-97.

Edmondson W.T. (1960) Reproductive rates of rotifers in natural populations. Instituto Italiano di Idrobiologia Memorie, 12, 21-77.

Edmondson W.T. (1968) A graphical model for evaluating the use of the egg ratio for measuring birth and death rates. Oecologia, 1, 1-37.

Frank P.W. (1960) Prediction of population growth form in Daphnia pulex cultures. American Naturalist, 94, 357-372.

Fryer G. (1957) The food of some freshwater cyclopoid copepods and its ecological significance. Journal of Animal Ecology, 26, 263-286.

Hairston N.G., Jr (1979) The adaptive significance of color polymorphism in two species of Diaptomus (Copepoda). Limnology and Oceanography, 24, 15-37.

Hutchinson G.E. (1967) A Treatise on Limnology, Volume 2. Wiley, New York.

Kerfoot W.C. (1977) Implications of copepod predation. Limnology and Oceanography, 22, 316-326.

Korstad J.E. (1980) Laboratory and field studies of phytoplankton-zooplankton interactions. Ph.D. thesis, University of Michigan.

Lampert W. (1977) Studies on the carbon balance of Daphnia pulex as related to environmental conditions. II. The dependence of carbon assimilation on animal size, temperature, food concentration, and diet species. Archiv für Hydrobiologie Supplement, 48, 310-335.

Leslie P.H. (1948) Some further notes on the use of matrices in population mathematics. Biometrika, 35, 213-245.

Lewontin R.C. (1965) Selection for colonizing ability. The Genetics of Colonizing Species (Eds H. G. Baker and G. L. Stebbins), pp. 79-94. Academic Press, New York.

Lotka A.J. (1925) Elements of Physical Biology. Williams \& Wilkins, Baltimore.

Lynch M. (1977) Fitness and optimal body size in zooplankton populations. Ecology, 58, 763-774.
Lynch M. (1980a) The evolution of cladoceran life histories. Quarterly Review of Biology, 55, 23-42.

Lynch M. (1980b) Predation, enrichment, and the evolution of cladoceran life histories: a theoretical approach. American Society of Limnology and Oceanography Special Symposium, 3, 367-376.

Lynch M. (1982) How well does the EdmondsonPaloheimo model approximate instantaneous birth rates? Ecology, 63, 12-18.

Meats A. (1971) The relative importance to population increase of fluctuations in mortality, fecundity, and the time variables of the reproductive schedule. Oecologia, 6, 223-237.

O'Brien W.J., Slade N.A. \& Vinyard G.L. (1976) Apparent size as the determinant of prey selection by bluegill sunfish (Lepomis macrochirus). Ecology, 57, 1304-1310.

Paloheimo J.E. (1974) Calculation of instantaneous birth rate. Limnology and Oceanography, 19, 692694.

Park R.A., O'Neill R.V., Bloomfield J.A.. Shugart H.H., Booth R.S., Goldstein R.A., Mankin J.B., Koonce J.F., Scavia D., Adams M.S., Clesceri L.S., Colon E.M., Dettmann E.H., Hoopes J., Huff D.D., Katz S., Kitchell J.F., Kohberger R.C., LaRow E.J., McNaught D.C., Peterson J., Titus J., Weiler P.R., Wilkinson J.W. \& Zahorcak C.S. (1974) A generalized model for simulating lake ecosystems. Simulation, 23, 33-50.

Pastorok R.A. (1980) Selection of prey of Chaoborus larvae: A review and new evidence for behavioral flexibility. American Society of Limnology and Oceanography Special Symposium, 3, 538-554.

Richman S. (1958) The transformation of energy by Daphnia pulex. Ecological Monographs, 28, 273291.

Robertson J.R. \& Salt G.W. (1981) Responses in growth, mortality, and reproduction to variable food levels by the rotifer, Asplanchna girodi. Ecology, 62, 1585-1596.

Scavia D. \& Park R.A. (1976) Documentation of selected constructs and parameter values in the aquatic model CLEANER. Ecological Modelling, $2,33-58$

Seitz A. (1979) On the calculation of birth rates and death rates in fluctuating populations with continuous recruitment. Oecologia, 41, 343-360.

Sinko J.W. \& Streifer W. (1967) A new model for age-size structure of a population. Ecology, 48, 910-918.

Slobodkin L.B. (1954) Population dynamics in Daphnia obtusa Kurz. Ecological Monographs, 24, 69-88.

Steele J.H. \& Frost B.W. (1977) The structure of plankton communities. Philosophical Transactions of the Royal Society of London, B. 280, 485-534.

Streifer W. (1974) Realistic models in population ecology. Advances in Ecological Research, 8, 199 266.

Strickler J.R. (1975) Intra- and interspecific information flow among planktonic copepods: Receptors. International Association of Theoretical and Applied Limnology Verhandlungen, 19, 29512958. 
Taylor B.E. \& Slatkin M. (1981) Estimating birth and death rates of zooplankton. Limnology and Oceanography, 26, 144-159.

Threlkeld S.T. (1979) Estimating cladoceran birth rates: the importance of egg mortality and the egg age distribution. Limnology and Oceanography, 24, 601-612.

Von Foerster H. (1959) Some remarks on changing populations. The Kinetics of Cellular Proliferation (Ed. F. Stohlman, Jr), pp. 382-407. Grune \& Stratton. New York.

Werner E.E. \& Hall D.J. (1974) Optimal foraging and the size selection of prey by the bluegill sunfish (Lepomis macrochirus). Ecology, 55, 1042-1052.

Zaret T.M. (1980) The effect of prey motion on planktivore choice. American Society of Limnology and Oceanography Special Symposium, 3, $594-603$.

Zaret T.M. \& Kerfoot W.C. (1975) Fish predation on Bosmina longirostris: visibility selection versus body-size selection. Ecology, 56, 232-237.

(Manuscript accepted 12 September 1982) 
This document is a scanned copy of a printed document. No warranty is given about the accuracy of the copy. Users should refer to the original published version of the material. 